\title{
Social Networking to Support Collaborative Interactions in Special Education
}

\author{
doi:10.3991/ijet.v5i2.1142 \\ C. Karagiannidis ${ }^{1}$, S. Efraimidou ${ }^{1}$ and A. Koumpis ${ }^{2}$ \\ ${ }^{1}$ University of Thessaly, Volos, Greece \\ ${ }^{2}$ ALTEC Software S.A., Thessaloniki, Greece
}

\begin{abstract}
This paper proposes a framework for the collaboration of teachers in special education. The framework builds on, and extends, social networking services, in order to facilitate collaboration amongst the various categories of stakeholders. The innovation of our approach lies, according to our view, in providing a Service Model and a platform for social networking by using WS directly the needs of individual users. Although simple and efficient WS creation tools already exist, our idea focuses on allowing teachers to socially interact with each other -based on WS creation and use- and to create value for themselves and the community.
\end{abstract}

Index Terms-special education, collaboration, social networking.

\section{INTRODUCTION}

The purpose of the proposed framework is to create a social networking platform that allows users to create, search, mash-up, publish, use, tag and rate services. The platform targets two primary types of users:

1. Individual users who may, for example, be parents of schoolchildren who want to use existing services or have access to information regarding the progress of their children.

2. Professional users that create and make their services available in the platform for networking or collaborative purposes with other professionals. Professionals can be teachers of general or special education as well as school management and / or administrative staff or other experts whose help may be asked, including, for example speech therapists, psychologists or other educational specialists.

We introduce an innovative Service Model that provides benefits to each distinctive type of user.

1. The platform allows individual users to:

a. Create a profile

b. Access their own personal services.

c. Tag their specific services.

d. Search for, and rate services provided by other users.

2. The platform allows professional users, besides service creation, to:

a. Define access rights, chargeback mechanisms and Service Level Agreements.

b. Create awareness of their profile, market services and their overall profile.

The platform is based on Service Oriented Architecture standards and Web Service (WS) technologies, aiming to be open, scalable and interoperable. In the back end, the WS infrastructure supports the Service Model. In the front end, a simple and easy-to-use Web 2.0 interface allows users to fully exploit the benefits of the platform.

We aim to develop a 'business' model for both mediating services and professional users that will be able to define service ownership, operations and maintenance. The platform prototype and its service model has been tested in full with a number of public users, as well as three separate use case scenarios on which we shall report in the future, as currently the evaluation exercise is still undergoing.

The innovation of our approach lies, according to our view, in providing a Service Model and a platform for social networking by using WS directly for the needs of the individual users. Although simple and efficient WS creation tools already exist, our idea focuses on allowing teachers to socially interact with each other -based on WS creation and use- and creating value for themselves and the community.

\section{BASIC CONCEPTS AND IDEAS}

The purpose of the proposed framework is to create a social networking platform that allows users to create, search, mash-up, publish, use, tag and rate services. The platform targets two primary types of users:

We all witness the enormous success of many social networking services which meet personal needs of friendship (Facebook), concise text-based communication (Twitter), professional networking (LinkedIn), bookmarking (Delicious), sharing videos (YouTube) and pictures (Flickr). The success of these services rests on the user/client/consumer being able to actively participate in a manner which is of personal benefit, thereby creating value for himself/herself.

Our aim is to follow up on the success of these services and create additional value for the teacher as the user of such an infrastructure and the wider community, in terms of facilitating the creation, mashing-up, publishing, tagging, using and rating services in a simple and userfriendly interface. Whereas Flickr concentrates on pictures and YouTube concentrates on videos, our idea is to concentrate on (web) services created for and by teachers within a social networking environment.

In this respect, our aim is to provide a social networking platform for developing services which address the needs of the teachers (with an emphasis to the collaboration between general and special education staff) and enable them to create value. 
In our initial phase, we envisage two main types of users using the service platform:

1. Novice, inexperienced teachers without any technical knowledge or programming expertise.

2. Power, experienced users aiming to promote their own services.

We aim to:

- Help education experts create services to meet their needs.

- Dynamically integrate education experts' (both from general and special education) multidimensional profiles

- Provide a roadmap for creating social networking services to support service provision

- Exploit the wisdom of the crowds ('crowdsourcing') in providing better services for professional users, while at the same time promoting open innovation and enhancements for service providers.

On the latter, we have reported extensively in (Karagiannidis et al, 2007) and (Karagiannidis et al, 2008). Versatility is a central attribute of the Framework, enabling the consumption of services which should address needs in a complex and highly distributed networked environment which can be seamlessly integrated with the current web.

The objective for this Framework is to be a major driver for large scale exploitation, enabling users to create, share and configure services easily which address their and others' needs, whether for entertainment, information, business or any other area, if possible, on a national scale covering the entire territory of Greece.

More specifically, our idea is to define a Framework for service provision based on educators' needs. This requires a well defined concept of service which we currently define as: "service is any item or action an education expert can offer which could meet the needs of that or another education expert either from the field of general education or from the field of special education”. The Framework is need-driven from the user aspect in order to provide 'made-to-fit' personalized services - rather than non- customised 'one-size fits all' solutions.

The concept of the Framework is depicted in Figure 1, which shows that a person with a particular need can use a solution from a network of people and services. The evolution, expansion and healthy functioning of this network depend on the ability of individual experts or organizations, such as the local or regional Offices of General or Special Education, to add their services to the network. The functions are complemented by feedback and rating of the utilized services (ultimately promoting open innovation and enhancing service quality), as illustrated in the figure.

The Framework enables the implementation of social networking services which support both networking for their users (as does Facebook) and provide services by individuals or organizations. These services can also be networked and mashed-up. Mashing-up services, i.e. combining data or functionality from two or more external sources to create a new service, in a social network fashion, can facilitate the selection and composition of services to address complex social and education needs.
People are multidimensional and multifaceted and defining the range of these complex aspects would be necessary in order to enable to locate and use the appropriate service. Personal profiles and service tagging vary from short and simple to complex and detailed.

We are specifically interested in the provision of a formalized structure for supporting service discovery, selection and composition (mashing-up), together with the relevant social networking functions (tagging, blogging, reviewing and rating).

Research into the categorization of services is essential. This includes the division into the educator's personal needs and the needs of the organization that he/she is part of. The idea of a Framework for networked services which is open to anyone in practice may seem too ambitious and easy to compromise, however the wisdom of the crowds in social networking services has helped to override such problems (e.g. in Wikipedia where false information is quickly corrected by others or a warning is provided regarding its reliability). Such approaches ensure the quality and monitoring of level of service.

The Service Framework aims to become a roadmap for developing open service-provision services of the Web 2.0 genre, maintaining enough versatility to eventually address provision of needs in the upcoming Web 3.0, where semantic considerations are of importance. To this end, we develop an open architecture that allows incorporation of semantic functionalities where needed.

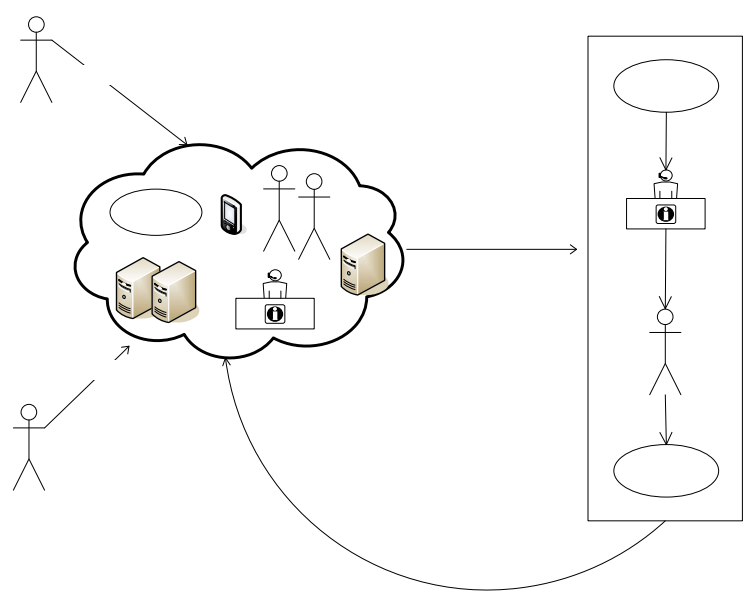

Figure 1. The proposed Social Networking Service Framework
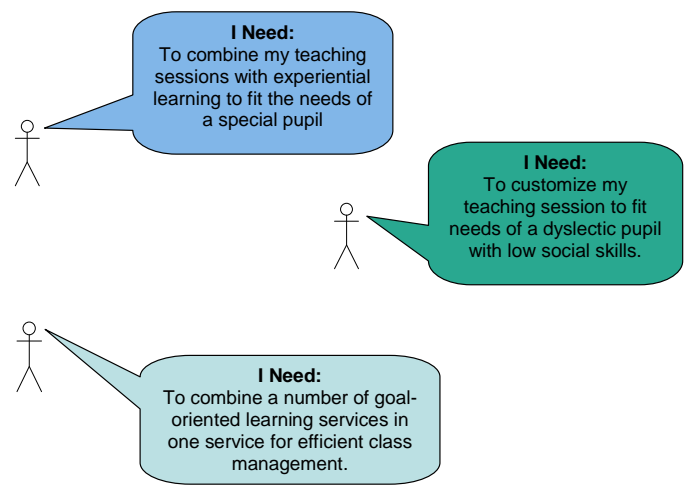

Figure 2. Need Examples 


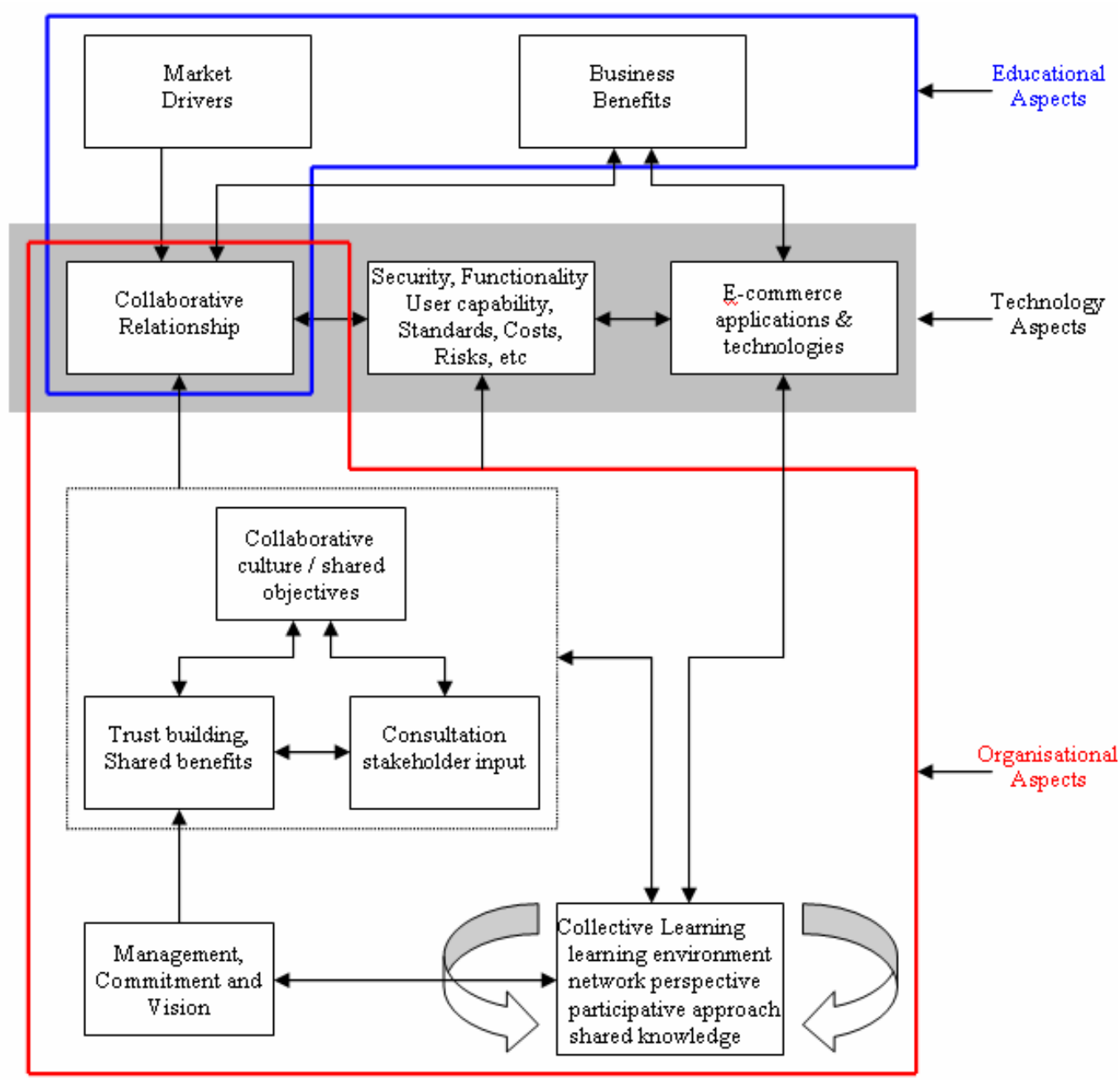

Figure 3. Framework to accommodate needs of the educators and the learners community

In the Figure above we present a conceptualization of the areas that we concentrated for the evolutionary building of our framework, demonstrating the progress towards more soft aspects of the interaction and networking activity as such.

It is interesting to recognise that the emergence of social networking principles is a spontaneous and unplanned to a great extent. Over the last few years, the rise of social software and social networking has driven the transition from content-centred to people-centred activities. 'Reading' and top down content production has dominated the first era of the Internet. Now a truly participatory bottom up or 'read/write' approach is emerging as a dominant trend. This shift of focus represents as much a cultural phenomenon as a technological one and has resulted in many commentators questioning its impact on our sense of identity, the meaning of community and the nature of this change (e.g. Hatzipanagos \& Warburton, 2009).

Web 2.0 has moved beyond the original meaning of the term defined by O' Reilly (2005) to encompass a set of tendencies exhibited by virtual communities. According to O’ Reilly (in Musser, 2006), Web 2.0 is a set of economic, social and technology trends that are based on user participation, openness and network effects. It is beyond doubt that consumer-oriented concepts can easily grow in such an environment. For instance, the best-known success stories of Web 2.0 (e.g. Wikipedia, Facebook, YouTube, etc.) are based on the concept of user participation through social networking.

The terms Web 2.0 and social software and social networking are often used together or synonymously, though Web 2.0 describes more the new ways in which the WWW is used, while social software and social networking, built on Web2.0 platforms and services, describes the universe of possible interactions between individuals and communities, where users are connected and collaborate with each other. The attitudes and behaviours of these communities or social groups have become as significant as the distributed technological platforms that are being exploited by increasing numbers of internet users.

One of the major characteristics of these new practices has been a shift towards 'user-generated content' where:

1. Collective and collaborative information is gathered, shared, modified and redistributed in creative acts;

2. Personal sites and content increasingly belong to the so called 'me media' category;

3. The user controls the choice of appropriate software, tools and services;

4. The 'collective intelligence' of users is harnessed through aggregation and large-scale cooperative activities (O’ Hear 2005). 
For example, social networking sites have become integrated into the daily practice of millions of users and Boyd and Ellison (2007) describe the key features of these services as allowing individuals to:

5. construct a public or semi public profile within a bounded system

6. articulate a list of other users with whom they share a connection, and

7. view and traverse their list of connections and those made by others within the system.

In general what we identify are two important functions of these social networks:

- Intelligence gathering, where people share and construct information online

- Meeting new people, where there are opportunities for one to one and one to many and many to many interactions.

Participants in internet-based social networking are immersed in fragmented digital environments, and engage in acts of computer mediated communication (Hatzipanagos 2006) through e-mail, email-conferencing and mobile texting, podcasting, personal publishing via blogs and wikis, aggregation and mash-ups, voice, chat, instant messaging and videoconferencing. Social networking is productive of and exercised by virtual communities of people with common interests. Users have the opportunity to contribute to personal and informal or professionally oriented social networks and the goal can be employment, provision of a service or collaboration.

The term community has been expanded to include interdependency and a set of relationships that connect people and groups. Citizens become Netizens, an identity that relates them to the entire world, and moves them outside their local life and work settings. For example, social networking, such as Facebook, MySpace, SecondLife and LinkedIn have changed forever the way people communicate in formal (professional) or informal spaces.

In all these cases, instead of business-generated content, we see user-generated content; the users contribute directly or indirectly and collectively co-create content or experiences. The users are not only consumers, but also co-developers; they do not expect the passive fulfilment of their needs by business firms. Instead, they participate actively in the development of products and services that meet their needs. Their motives for participation are related to their needs to create products, services and websites that fulfil their personal interests, to tailor offers according to their preferences, to experiment, learn and gain experiences, to contribute to the community, to offer to their peers and to communicate and share with others.

\section{CONCLUSIONS}

In recent years the gap between educational theory and practice has been closing, but although there have been calls for 'reflexivity', there has been little critical examination of its meanings. Proposed reflexive methodologies still perpetuate many traditional hierarchies and fail to consider the creative nature of the educational process as such. Much research work also takes place within the commercial sphere, and post-processual ideas cannot advance educational practice unless they can be implemented in some type of an e-learning system. In our paper we examined the idea of employing a social networking platform to allow for collaboration amongst education experts.

Even if several educational services exist, these services are still un-configurable by the education expert and represents professional ('business') logic that does not consider the specific needs of the particular pupils. These services are designed in a manner that allows no or extremely low customization to reflect the actual needs of the individual pupils. Though this reality is more or less widely adopted in the domain of general education, the needs for individualized interventions in the area of special education form the rule rather than the exception. The implications of this to the technical architecture of any plausible solution should take into account the following three dimensions:

1. Inter-school unit dimension: This represents the overlap among processes and practices from a set of intra-organizational school units. This overlap is usually the result of necessary interaction between processes, which can be explicit or implicit. However, this interaction is not subject to a series of sequential activities but may occur between any of the entire set of activities running into the particular school organization. Indeed, all professional knowledge is not spread according to the activity's predefined sequence. These interactions can exist between the same school unit, or two or more different school units.

2. Cross-level Intra-school unit dimension: This represents the common knowledge of members of the same school unit level but from different environments. This set is the federator of the community of participants in the activities and processes of the school units involved. This knowledge is generally specific to the particular unit and related to the various underlying or supporting processes that lead to the difficulty to find it beyond its area of competencies. It represents the relay points between the various stages of implementing collaboration, as well as the enforcement or the establishment of one or more processes of the unit. This knowledge is often at a high level of granularity and is sometimes extracted directly from the environment of process enforcement. This high level of specialization infers their reduced interoperability with other units of the same school organization. Still, this knowledge is compulsory for the functioning of processes within the unit and is usually transplanted into other environments under other forms.

3. Cross level-Inter unit dimension: Depending on the particular environment of the school organization, the distribution of its inherent processes can vary significantly in scheduling, operating or its prerequisites. Nevertheless, school units that contain these processes can be matched with other school units from a different environment in terms of needs, knowledge or skills. This knowledge can be a source of innovation and discovery. Indeed, a result of this knowledge is generally the use of a new form of knowledge completely different from the most commonly used one in this area. This makes the 
overlap very diverse, unstructured and thus hardly detectable compared to other levels of overlap.

Our approach can be considered a further stage of evolution that connects knowledge, and represents meanings and knowledge about things so that educational experts can work together, adding new levels of intelligence to the user interface of existing (operational) systems, collaboration applications, and the infrastructure of the Web.

\section{REFERENCES}

[1] Boyd, d. and Ellison, N.B. (2007). Social Network Sites: Definition, History, and Scholarship.

[2] C. Karagiannidis, S. Efraimidou, A. Koumpis, F. Molinari, A Collaborative Community Environment to Support Experiential Improvement of Processes and Practices in Special Education, 4th WSEAS / IASME International Conference on Engineering Education (EE'07), Agios Nikolaos, Crete Island, Greece, July 2426, 2007

[3] C. Karagiannidis, S. Efraimidou, A. Koumpis, F. Molinari, Employing the Living Labs methodology to support experiential improvement of processes and practices in special education, 6th International Conference on Networked Learning 2008, 5 - 6 May 2008, Halkidiki, Greece

[4] Hatzipanagos, S. \& Warburton, S. (Eds) (2009) Social Software and Developing Community Ontologies (London: Information Science Reference, an imprint of IGI Global).
[5] Hatzipanagos, S. (2006). HOT and Flaming Spirals: Learning and Empathic Interfaces in Text-based Discussion Forum Dialogues. European Journal of Open, Distance and e-Learning, 2006/I.

[6] Musser, J. (2006). O'Reily Radar: Web 2.0 Principles and Best Practices. O’Reilly Media Inc.

[7] O'Hear, S (2006). Web's second phase puts users in control, Tuesday June 20 2006, The Guardian Education. Accessed online from http://education.guardian.co.uk/elearning/story/0,180108 6,00.html on 21 November 2008.

[8] O'Reilly, Tim. 2005. What Is Web 2.0: Design Patterns and Business Models for the Next Generation of Software. http://www.oreillynet.com/pub/a/oreilly/tim/news/2005/09/30/wha t-is-web- Oriented-Economy20.html. Retrieved: 12/4/2009.

\section{AUTHORS}

C. Karagiannidis is an Assistant Professor at the University of Thessaly, Department of Special Education, Greece (e-mail: karagian@uth.gr).

S. Efraimidou is a $\mathrm{PhD}$ candidate at the University of Thessaly, Department of Special Education, Greece (email: seffraim@sch.gr).

A. Koumpis is the Director of Research Programmes at ALTEC Software, S.A., Greece (e-mail: akou@altec.gr).

Manuscript received November $6^{\text {th }}$ 2009. Published as resubmitted by the authors May $24^{\text {th }} 2010$. 